\title{
Generación de engagement con un servicio de vídeo bajo demanda en Twitter. El caso de Netflix España
}

Generation of engagement with a video on demand service on Twitter. The case of Netflix Spain

\section{Geração de engajamento com um serviço de vídeo sob demanda no Twitter. $O$ caso da Netflix Espanha}

\author{
Mónica Herrero Subías ${ }^{1}$ \\ Universidad de Navarra (España) \\ moherrero@unav.edu \\ Alicia Urgellés Molina ${ }^{2}$ \\ Universidad de los Hemisferios (Ecuador) \\ amurgellesm@profesores.uhemisferios.edu.ec
}

Fecha de recepción: 06 de febrero de 2018

Fecha de recepción evaluador: 30 de septiembre de 2018

Fecha de recepción corrección: 14 de noviembre de 2018

\footnotetext{
${ }^{1}$ Mónica Herrero es Decana de la Facultad de Comunicación de la Universidad de Navarra y profesora de Empresa Informativa y Estructura del Periodismo. Obtuvo el Doctorado Europeo en 2002 y es Master en Media Management por la University of Stirling (Escocia). Fue Vicedecana de la Facultad de Comunicación desde 2004 hasta el 2008. Su actividad investigadora se centra en la economía de los productos audiovisuales y los mercados de la comunicación.

${ }^{2}$ Alicia Urgellés Molina es doctora en Ciencias de la Comunicación por la Universidad de Navarra. Actualmente es directora, coordinadora y docente de la Facultad de Comunicación de la Universidad de Los Hemisferios.
} 


\title{
Resumen
}

Las cadenas de televisión han visto en el uso de las redes sociales una oportunidad para favorecer la relación con sus audiencias y conocerlas mejor, y esto ha sido objeto de interés de la profesión y la academia. También lo ha sido el uso de Twitter como parte de su estrategia de comunicación. El desarrollo de los servicios audiovisuales bajo demanda, que alteran los patrones de consumo tradicional, sugiere un marco diferente en estudio del uso de las redes sociales, Twitter en particular.

El objetivo de este estudio es el análisis del discurso que mantiene Netflix en la red social Twitter. Nos preguntamos cómo se relaciona la marca con los consumidores fuera de su canal propio -su aplicación, su plataforma-. Es decir, qué tipo de conversaciones mantiene en un espacio público, si lo hace; en qué se centran esas conversaciones y cuál es el peso de los contenidos de su catálogo en ellas. Para ello, combinaremos la creación de un marco teórico para la comprensión del uso de Twitter en un servicio de video bajo demanda con el estudio del caso de Netflix España centrándonos en un mes concreto al año siguiente de su lanzamiento. El objetivo final consiste en extraer tendencias que apunten a prácticas paradigmáticas para el mantenimiento de una relación de engagement a través de Twitter en un servicio de video bajo demanda.

Palabras clave: televisión, redes sociales, audiencias, servicio de video bajo demanda, Twitter, Netflix, consumo, engagement

\begin{abstract}
The television networks have seen in the use of social networks an opportunity to favor the relationship with their audiences and to know them better, and this has been an object of interest for the profession and the academy. So has the use of Twitter as part of their communication strategy. The development of on-demand audiovisual services, which alter traditional consumption patterns, suggests a different framework in the study of the use of social networks, Twitter in particular.

The objective of this study is the analysis of the discourse maintained by Netflix on the social network Twitter. We ask ourselves how the brand relates to consumers outside its own channel - its application, its platform. That is, what kind of conversations you have in a public space, if you do so; what these conversations are focused on and what is the weight of the contents of their catalog in them. To do this, we will combine the creation of a theoretical framework for the understanding of the use of Twitter in a video on demand service with the case study of Netflix Spain focusing on a specific month the year after its launch. The final objective is to extract trends that point to paradigmatic practices for the maintenance of a relationship of engagement through Twitter in a video on demand service.
\end{abstract}

Keywords: television, social networks, audiences, video on demand service, Twitter, Netflix, consumption, engagement 


\section{Resumo}

As redes de televisão viram no uso das redes sociais uma oportunidade de favorecer o relacionamento com seus públicos e conhecê-los melhor, e isso tem sido um objeto de interesse para a profissão e para a academia. Então, tem o uso do Twitter como parte de sua estratégia de comunicação. O desenvolvimento de serviços audiovisuais sob demanda, que alteram os padrões tradicionais de consumo, sugere uma estrutura diferente no estudo do uso de redes sociais, particularmente o Twitter.

O objetivo deste estudo é a análise do discurso mantido pela Netflix na rede social Twitter. Perguntamo-nos como a marca se relaciona com os consumidores fora de seu próprio canal - sua aplicação, sua plataforma. Isto é, que tipo de conversas você tem em um espaço público, se você fizer isso; em que essas conversas são focadas e qual é o peso do conteúdo de seu catálogo nelas. Para fazer isso, combinaremos a criação de uma estrutura teórica para a compreensão do uso do Twitter em um serviço de vídeo sob demanda com o estudo de caso da Netflix Espanha, com foco em um mês específico no ano após o seu lançamento. O objetivo final é extrair tendências que apontem práticas paradigmáticas para a manutenção de uma relação de engajamento através do Twitter em um serviço de vídeo sob demanda.

Palavras-chave: televisão, redes sociais, audiências, serviço de video on demand, Twitter, Netflix, consumo, engajamento

\section{Introducción}

El uso generalizado de las redes sociales es visto por muchas empresas de medios como una forma de promover sus marcas y, en última instancia, establecer un vínculo con cada persona de sus públicos. Dentro del campo de las Relaciones Públicas, por ejemplo, se ha estudiado el uso de los social media en las organizaciones, y la forma en que están cambiando la comunicación con los públicos estratégicos.

En este contexto de las redes sociales se ha extendido el uso de la palabra engagement para hablar de la relación que mantienen los usuarios en estos espacios, conversando con periodistas, creadores de contenido, comentando y compartiendo mensajes. Al mismo tiempo, en la investigación sobre las audiencias de televisión, destaca el estudio de la 'audiencia social'. El reflejo en las redes sociales de las opiniones sobre los programas puede complementar y enriquecer el conocimiento de los creadores $\mathrm{y}$ gestores de contenido cuando la medición tradicional se complica al fragmentarse y dispersarse las audiencias.

Sin embargo, en este artículo no estudiaremos la audiencia social o las ventajas que esta aporta en datos cuantitativos a la medición tradicional. El objetivo de este estudio es el análisis del discurso que mantiene Netflix con sus usuarios en redes, concretamente en la red social Twitter. Nos preguntamos cómo se relaciona la marca con los consumidores fuera de su canal propio -su aplicación, su plataforma-. Es decir, qué tipo de conversaciones mantiene en un espacio público, si lo hace; en qué se centran esas conversaciones; cuál es el peso de los contenidos de su catálogo en ellas. 
Para ello, realizaremos una revisión de la literatura que nos permita construir un marco teórico para la comprensión del uso de Twitter en un servicio de video bajo demanda como Netflix. Esta será la principal aportación teórica de este trabajo. Será necesario acudir a la naturaleza del servicio que estudiamos, a las teorías de relaciones públicas y a los estudios que se fijan en la relación de Twitter con las audiencias de televisión.

El análisis del caso nos llevará a estudiar los tuits de la cuenta de Netflix en España durante un mes. Netflix opera en España desde octubre de 2015, y la cuenta oficial de Netflix en Twitter para España es @NetflixES. Se abrió en abril de 2015, actualmente tiene más de 515,000 seguidores y a finales de 2016 tenía más o menos 120,000. Netflix tiene alrededor de 24 perfiles en Twitter correspondientes a cada país o región en la que se encuentra en servicio, así como una cuenta de servicio al cliente, @Netflixhelps, que cumple una función de canal de comunicación con el servicio técnico a nivel internacional.

Para el presente análisis se observan un total de 306 tuits correspondientes a un solo mes, el de octubre de 2016. Se eligió este mes por ser el del primer aniversario de la llegada de la plataforma a España; también por ser un mes intermedio entre el inicio de las temporadas en televisión y la época de Navidad y fin de año -épocas en las que, tradicionalmente, habría más información sobre nuevos lanzamientos. El objeto de interés son los mensajes de la cuenta de Netflix y sus contenidos. En este sentido, el presente análisis tiene la limitación de centrarse en la perspectiva de la marca. En el futuro, para completar este estudio, podría repetirse el análisis dando mayor importancia a las cuentas con las que interactúa @NetflixES.

Además de ver la estrategia concreta detrás de las publicaciones de ese periodo de tiempo, se pretende extraer tendencias dentro del marco del uso de Twitter, que apuntarán a prácticas paradigmáticas para el mantenimiento de una relación de engagement en un servicio de video bajo demanda.

\section{Marco teórico}

Siendo el objeto de nuestro estudio el discurso que Netflix España tiene en la red social, convendrá abordar este marco teórico desde diferentes perspectivas. Como servicio televisivo, revisaremos la literatura sobre el uso de Twitter por parte de las cadenas de televisión, con las particularidades de un servicio bajo demanda. Por otro lado, será necesario fijarnos en el uso de Twitter como instrumento de comunicación corporativa, ya que el objeto de nuestro estudio es el discurso de Netflix, que no deja de ser una compañía y una marca.

Desde el nacimiento de la red social, el uso de Twitter por parte de las cadenas de televisión ha sido objeto de la investigación académica (Greer \& Ferguson, 2011; Wood \& Baughman, 2012). Desde el ámbito de los estudios de recepción y audiencias, se destaca el potencial de la red social para conocer así mejor a las audiencias y su relación con los medios (Deller, 2011). Otros autores ponen el énfasis en la conversación que tiene lugar entre las audiencias durante la emisión de esos contenidos. Se ha consolidado el 
concepto de "audiencia social", para referirse a los individuos que realizan menciones en una determinada red social sobre un contenido televisivo (González-Neira \& QuintasFoufe, 2015). De esta manera, las cadenas pueden combatir la inevitable fragmentación de las audiencias utilizando Twitter como segundo canal (backchannel) durante la emisión. Esto promueve el visionado en directo, porque una comunidad social se reúne en la misma plataforma a la misma hora (Highfield, Harrington, \& Bruns, 2013).

Algunos autores señalan también la necesidad de explorar el papel de Twitter con las audiencias en un contexto televisivo más amplio que el de los contenidos en directo. En esas circunstancias de consumo, el uso de Twitter por parte de las cadenas está dirigido a mantener una comunidad de fans y entusiastas que se comunican directamente con ellas o con los productores del programa (Harrington, Highfield, \& Bruns, 2013).

Precisamente en ese contexto televisivo más amplio se encuentran los servicios de video bajo demanda (SVOD). Un servicio de video bajo demanda, compartiendo muchas de las características de una cadena tradicional de televisión, posee unos elementos diferenciales especialmente relevantes. El debate académico y profesional sobre la naturaleza de la televisión es abundante (Lotz, 2007; Tryon, 2015). Lo que esencialmente todas las televisiones tienen en común es la actividad de programar, es decir, proveer unos contenidos en un espacio y tiempo determinados.

Los servicios de video bajo demanda ofrecen los contenidos superando los límites de espacio y tiempo (expresado en los conceptos placeshifting y timeshifting), y permiten un consumo personalizado e individualizado (Herrero, 2009). Parece claro, por tanto, que el uso de Twitter por parte de las audiencias difiere de alguna manera del concepto de audiencia social que comenta los programas mientras se están emitiendo y se acercará más al de los fans que hacen comentarios y preguntas sobre los contenidos directamente con la cadena. Aunque no existe literatura específica sobre el uso de Twitter por las audiencias de servicios de video bajo demanda, la revisión de la literatura sobre las cadenas de televisión y Twitter pone de manifiesto la centralidad de los contenidos como objeto de la relación.

En la misma línea de la centralidad de los contenidos, Jenkins, Ford y Green hablan sobre un cambio de paradigma en el consumo de medios y sobre cómo, para algunas audiencias, son más importantes los programas concretos que las plataformas o los contextos en los que los consumen. De acuerdo con los autores, es con estas audiencias con quien se puede entablar un "transmedia engagement", basado en contenidos que se pueden extender más allá de su contenedor inicial (Jenkins, Ford, \& Green, 2013). En estos casos, serían los programas, series o películas los verdaderos sujetos de la relación de engagement con las audiencias. Así, la marca del servicio tendría que ser capaz de aprovechar la relación que se genera gracias a los contenidos que distribuye para acercarse a sus usuarios.

El uso de Twitter puede formar parte de la estrategia de comunicación corporativa de las empresas. Algunos autores indican que si la función de la comunicación corporativa con los medios tradicionales se centraba en entregar mensajes, con las redes sociales la comunicación consiste en escuchar, conversar, y construir relaciones (Drury, 2008). La 
gestión de las relaciones (relationship management) ha sido un tema central en la investigación en Relaciones Públicas, y en los últimos años esta perspectiva de la relación se ha desarrollado en múltiples teorías (Li, 2015). Entre ellas, la teoría de la comunicación dialógica propuesta por Kent y Taylor, que proporciona un marco teórico que sirve de guía para la creación y mantenimiento de la relación entre una organización y sus públicos a través de la web (Kent \& Taylor, 1998). Otros autores han aplicado este marco teórico tanto en medios tradicionales como en redes sociales (Kim, Nam, \& Kang, 2010; Seltzer \& Zhang, 2010).

Especialmente interesantes son las aportaciones de autores que tratan el engagement con los usuarios de Twitter, aplicando la teoría de la comunicación dialógica (Lovejoy, Waters, \& Saxton, 2012; Rybalko \& Seltzer, 2010; Sundstrom \& Blake, 2017). Sin embargo, todavía es escasa la investigación que haya identificado estrategias de comunicación de las organizaciones en Twitter para potenciar el engagement y que haya demostrado la efectividad de las redes sociales como herramienta para construir relaciones (Saffer, Sommerfeldt, \& Taylor, 2013).

Por otro lado, cuando las empresas y organizaciones se relacionan con sus públicos y dialogan con ellos, lo hacen a través de sus marcas. El que los usuarios se relacionen con las marcas de forma similar a como se relacionan con otras personas facilita que se pueda hablar de la posibilidad de una relación de engagement con una marca. En este punto, la literatura es muy extensa y no es el objeto principal de esta investigación.

Desde la perspectiva dialógica, nos interesa fijarnos en algunos autores que destacan los elementos de personalización de las marcas. Aaker desarrolló el marco teórico de la personalidad de una marca desde cinco dimensiones, convirtiéndose en un trabajo de referencia (Aaker, 1997). Fournier añade que las marcas poseen unas características humanas, que hacen posible dicha relación (Fournier, 1998). Además, una ligera visión antropomórfica de la marca tendría sentido, puesto que, además de formar su personalidad a partir de la gente que se le asocia, la marca bajo la que se figura la organización está compuesta por personas y es producto de sus decisiones.

Las características de Twitter permiten dar voz a la marca, contribuyendo a la personalización, y por tanto a la humanización del diálogo y de la relación (Kelleher, 2009) entre la empresa y sus clientes. Por otro lado, como señalan Marwick y Boyd, Twitter sigue un modelo de amistad dirigida, que ni exige reciprocidad ni la espera (Marwick \& Boyd, 2011). Este modelo peculiar de amistad, que no requiere necesariamente el diálogo, pone de manifiesto lo que señala Watkins: quizá la audiencia de Twitter no está tan interesada en un modelo dialógico, sino en encontrar información útil, y esto es lo que finalmente, más que el diálogo, consigue el engagement (Watkins, 2017).

A la luz de la revisión realizada desde las distintas perspectivas, intentaremos avanzar en el marco conceptual del discurso de Netflix en la red social Twitter, para poder orientar el análisis del caso. Por un lado, en el caso de una cadena de televisión, la conversación habitual en Twitter, como hemos visto, versa sobre los contenidos. Debido 
a la personalización del consumo y, por tanto, la desvinculación temporal en Netflix, parece razonable que el discurso persiga tanto dar información útil sobre los contenidos y el servicio, como comentarios que contribuyan al engagement con dichos contenidos.

Por otro lado, debido a la naturaleza contractual de la relación con Netflix, y el pago que conlleva, no será de extrañar que Twitter sea también un lugar de conversación sobre temas relacionados con la provisión del servicio. En este sentido, el posicionamiento de marca de Netflix en algunos aspectos se acerca más al de otros servicios online como Google o Amazon que los tradicionales canales de televisión. El consumo individualizado (on demand) marca una diferencia fundamental (Jenner, 2016).

La marca, en su comunicación corporativa en Twitter, inicia una conversación en la que refleja su personalidad con voz propia. Esa voz no puede obviar el motivo principal de la conversación: los contenidos. En cierta manera esto determinará el tono de la conversación, que tiene por objeto historias que permiten el uso del humor, el suspense, etc., acercando el tono de la conversación a la que se tiene con un amigo.

\section{Estudio del caso}

\section{Metodología}

Como se ha señalado en la introducción, el análisis se centra en los 306 tuits de la cuenta@NetflixES durante el mes de octubre de 2016. La muestra se recogió por medio de anotaciones manuales realizadas por un codificador principal y contrastadas por un segundo codificador. Las anotaciones sobre la muestra fueron organizadas según 7 categorías descriptivas (1) tipo de tuit -publicación o respuesta a usuario-, (2) objetivo de la publicación -dar información o comentarios y opiniones- (3) tema del contenido principal del tuit, (4) si adjunta archivos o enlaces -imágenes, vídeo, GIF, etc.-, (5) referencias directas al catálogo, sus títulos y personajes, (6) número de retuits, likes y comentarios, y finalmente, (7) otras observaciones.

Para empezar, partimos de un examen cuantitativo de la muestra, con el fin de perfilar el tipo de contenidos que hemos observado. La muestra tiene una media mensual de 10 tuits al día. De los 306, un 75\% (229) son respuestas a menciones de otros usuarios de la red. Aunque la cuenta no responde a todas las menciones que le hacen, es interesante que la participación en las conversaciones de otras cuentas sume tres cuartos de sus publicaciones. El foco de nuestro análisis es el discurso de la marca, por lo que la selección que hace al responder solo a ciertas menciones forma parte del cuidado y la intencionalidad de ese discurso. Por tanto, aunque no es una visión representativa de los comentarios que se hacen sobre la marca en Twitter, es suficiente para mostrar lo que dice la marca de sí misma.

El presente estudio tiene algunas limitaciones. La primera está unida a la primicia que supone el caso de Netflix en el mercado, lo cual lleva a que sea único e inigualable en muchos aspectos. Otra limitación es que los resultados de este análisis son descriptivos, principalmente cualitativos y limitados a un mes concreto; no son una muestra cuantitativa de patrones de publicación de la cuenta ni de las opiniones de los usuarios sobre la marca. Asimismo, se eligió hacer la recogida de la muestra de forma 
manual para cuidar el estudio del contenido de las publicaciones y su categorización. Automatizar la recogida y el procesamiento de los tuits permitiría tal vez una ampliación de la muestra para un futuro estudio más exhaustivo.

\section{Análisis de resultados}

Según una encuesta a mil usuarios de la red social, mantenerse informado de lo que sucede en el mundo y compartir reflexiones e ideas con los demás son dos de los principales objetivos de los internautas para el uso de esta red (Delgado von Eitzen, 2016). Así, en cuanto al contenido de los tuits, señalamos en primer lugar si tiene un objetivo más informativo o si son comentarios.

Las publicaciones con un contenido informativo serían aquellas en las que la cuenta comparte información sobre el servicio, sus características y beneficios, nuevos productos del catálogo, etc. Por 'comentario' nos referimos al tipo de publicación en la que comparte reflexiones, ideas u opiniones o se responde a reflexiones, ideas u opiniones de los usuarios. Los resultados muestran que más tuits son comentarios que informativos (175 frente a 131). Sin embargo, a pesar de no estar ofreciendo información concreta, tienen una finalidad muy similar a los informativos en su carácter autorreferencial.

Un tuit puede contener fotos, vídeos, enlaces y un máximo de 140 caracteres de texto. El contenido visual es un componente habitual en las redes sociales y es fundamental en plataformas explícitamente enmarcadas alrededor de lo audiovisual como Instagram- y en aquellas que ofrecen una mezcla de texto e imágenes en múltiples formas, como Facebook o Twitter (Highfield \& Leaver, 2016). En el siguiente gráfico se puede ver qué formatos utiliza más la cuenta @NetflixEs en sus publicaciones.

Gráfico 1. Tuits según formato de los elementos adjuntos

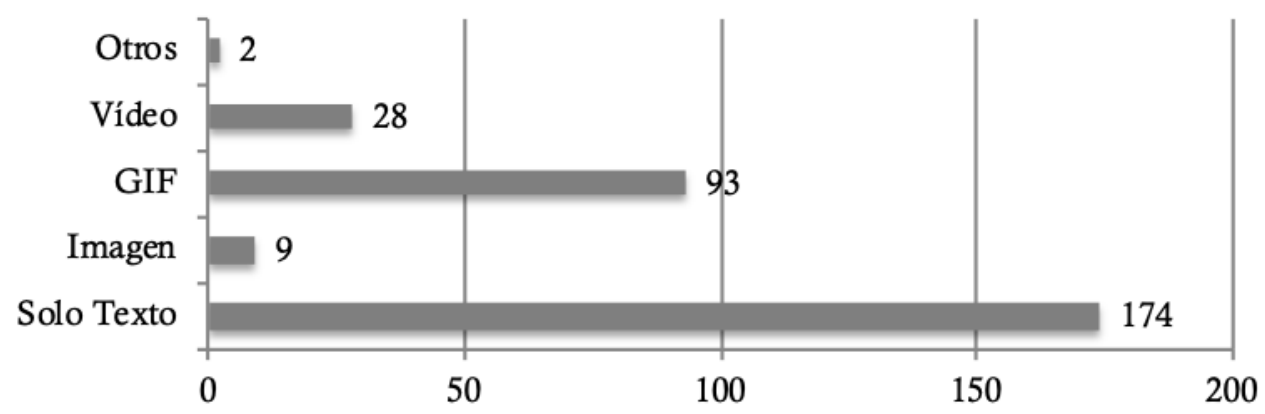

\section{Fuente: elaboración propia}

174 tuits $(57 \%)$ están compuestos por texto únicamente. Esto se podría considerar normal, teniendo en cuenta que el texto es el elemento base de la red social y necesario para dar información y responder preguntas. Podría verse como algo más curioso el que el vídeo esté presente en únicamente 28 de los 306 tuits (9\%) y que, en cambio, el siguiente elemento más utilizado en los tuits de la cuenta sean los archivos GIF (30\%).

El contenido de muchos GIF se suele extraer de películas o televisión y puede incluir texto, un diálogo de la película o serie de la que proviene. La elección de un GIF 
puede deberse a que el usuario se identifica con el contenido de la imagen y lo recoge sin dar importancia a la fuente original (Tolins \& Samermit, 2016). Sin embargo, supone un paso extra a favor de la identificación de la marca y con la marca si los interlocutores utilizan imágenes teniendo en cuenta a la fuente original, el contexto en que se produce el diálogo, etc. En resumen, este comportamiento señalaría una posible relación de engagement con los contenidos individuales que podría reforzarse y trasmitirse a la marca Netflix.

Una forma limitada de observar la reacción de los usuarios a las publicaciones de Netflix es a través de los 'retuits' y likes con los que interactúan con el contenido. Estos implican una reacción positiva al contenido de una publicación (De Vries, Gensler, \& Leeflang, 2012) por lo que nos sirve para tener una cuantificación sencilla de la aceptación de los mensajes de la marca. El siguiente gráfico (gráfico 2) presenta la media de 'retuits' y likes según el elemento principal de la publicación -si tiene adjunto un vídeo, imagen, GIF, etc o si es solo texto-.

Gráfico 2. Media de retuits y likes de las publicaciones de @NetflixEs según elementos adjuntos de la publicación

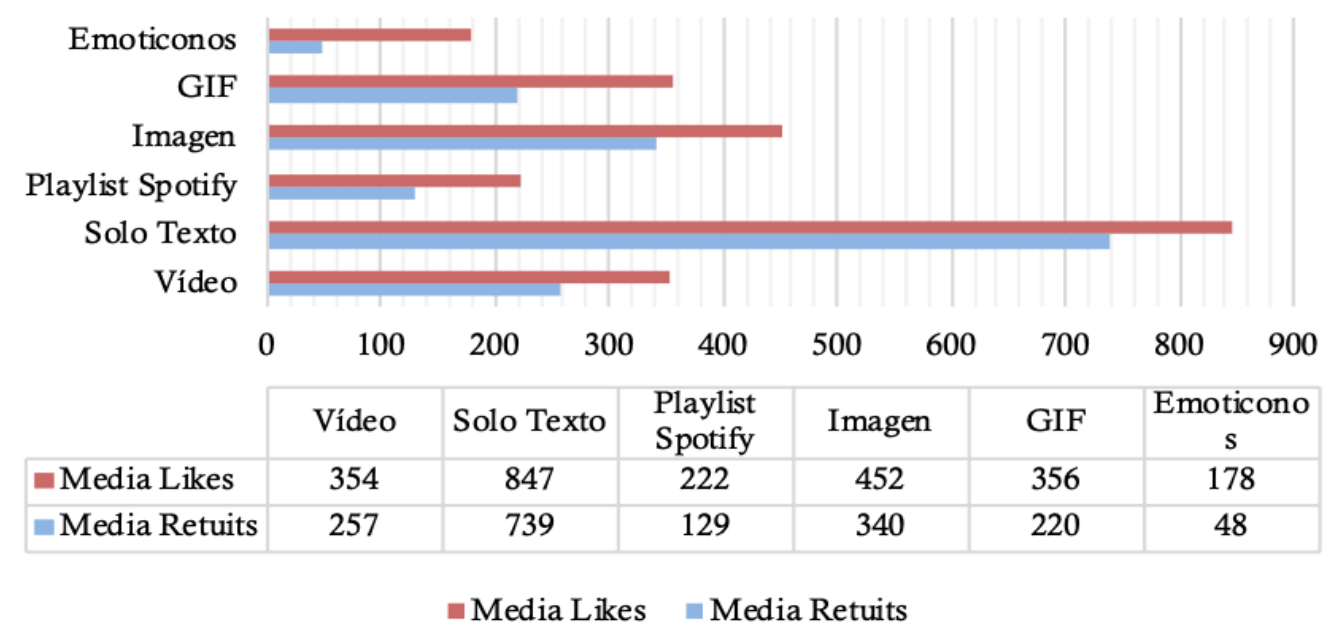

\section{Fuente: elaboración propia}

Se partía de la hipótesis de que los tuits más compartidos o preferidos por los usuarios serían aquellos con imágenes o GIFs, seguidos tal vez de aquellos que adjuntaran vídeos o tráilers. En promedio, los tuits compuestos únicamente por texto son los que cuentan con más likes y son más compartidos. Un ejemplo es el de la siguiente imagen:

Imagen 1. Tuit @NetflixES (3/10/2016)

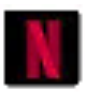

Netflix España @NetflixES - 3 oct. 2016

4815162342

h 222 t27 $2,4 K \cup 2,6 K$

Los números que aparecen en esta publicación de la imagen 1 constituyen uno de los temas recurrentes y más importantes de la serie Lost. Para quien no tenga conocimientos de la serie, esta publicación puede carecer de sentido, pero@NetflixEs utilizó este tuit para anunciar la llegada de la serie al servicio en España. Los seguidores 
de Lost en Twitter comprendieron el mensaje y se inició un diálogo al respecto en la red social. De hecho, este tuit es el más retuiteado y el que más expresiones de 'me gusta' recibe en todo el mes. Este ejemplo muestra cómo la cuenta utiliza referencias al contenido de una serie -no original de la marca, en este caso- para conectar con un público concreto de 'fans'.

Por otro lado, al comparar la media de 'retuits' y likes según el propósito de la publicación -comentario o informativa-, se observa que los comentarios son el tipo de publicación de@NetflixEs a la que los usuarios de Twitter respondieron más favorablemente: los comentarios tienen un promedio de 486 retuits y 623 likes, frente a los 178 retuits y 289 likes de las publicaciones informativas. Las tres publicaciones con más 'me gusta' del mes son también las más retuiteadas. La primera, la que vimos en la imagen 1 .

Esto nos adentra en el punto central de nuestro análisis: la temática principal de los tuits y su relación con el negocio principal. En el gráfico 3 se muestran los diez temas principales que se tratan en los tuits y el porcentaje que representan del total de las publicaciones estudiadas. Varios de estos temas hacen referencia de forma más evidente a un tuit de tipo informativo, como pueden ser los que están centrados en la disponibilidad presente o futura de contenido en el catálogo español. Otros, como las referencias a ciertos hábitos de consumo de los usuarios o las respuestas a comentarios de usuarios satisfechos estarían más unidos al tipo de tuit 'comentario'.

\section{Gráfico 3. Porcentaje de tuits según tema principal de su contenido}

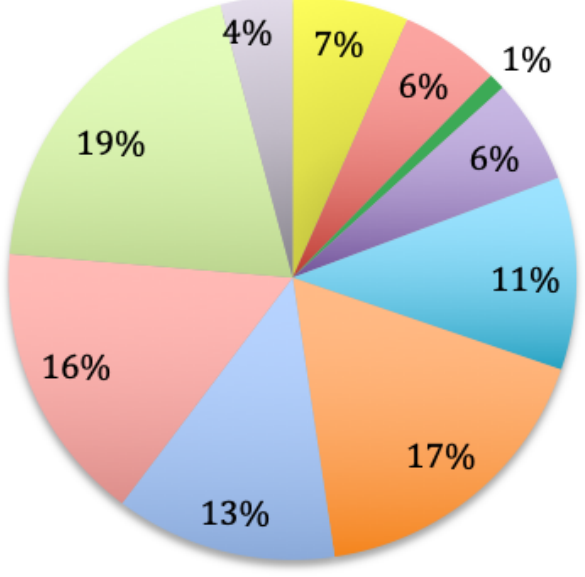

\footnotetext{
Anuncio futura disponibilidad de contenido

Notificación sobre contenido ya disponible

- Contacto con nuevo usuario

- Respuesta a expresión de satisfacción con contenido

- Respuesta a expresión de "amor" por Netflix

- Referencia a hábitos de consumo

Referencia a problema técnico

- Respuesta a pregunta sobre disponibilidad de contenidos

- Referencia general a contenido

a Respuesta a sugerencia para catálogo
}

Fuente: elaboración propia 
Según este gráfico, el tuit más recurrente es aquel en el que el tema principal es un comentario general sobre contenido del catálogo de Netflix (19\%), seguido por los que hacen referencias a los hábitos de consumo $(17 \%)$ y los que responden a preguntas de los usuarios sobre disponibilidad de algún título (16\%).

Resulta interesante que un porcentaje modesto de los tuits estudiados hacen referencia al "amor" de los usuarios por la marca (11\%). Las interacciones de este tipo tienen un tono emocional más que racional, pero también parecen tener, como catalizador, una experiencia satisfactoria de la oferta.

Aunque el gráfico 3 muestre que solo un 19\% de los tuits tiene como tema central un comentario general sobre algún contenido del catálogo, muchos otros tuits contienen referencias a los contenidos en forma de imagen, vídeo o GIF. Concretamente, del total de los 306 tuits, en 234 (76\%) o se mencionan en el texto personajes, títulos, tramas de los contenidos o se añade una imagen complementaria extraída de los mismos. Significa que un $76 \%$ de las interacciones de la cuenta en redes sociales se apoyan de una forma $u$ otra en los contenidos, ya sea porque tienen su origen en la información que la cadena quiere ofrecer de ellos o que los usuarios piden, o porque se utilizan referencias a ellos para apoyar otros comentarios.

Como decíamos anteriormente, los GIF son una forma de apoyarse en las historias y personajes de las que dispone el servicio. El uso común de las imágenes para reproducir la que sería la acción del emisor del mensaje resulta especialmente interesante en este caso de Netflix, que no es una persona, sino una marca.

Se aprovechan estos elementos en las conversaciones de la marca con los públicos de la red para reforzar una relación similar a la que se podría mantener con una persona, como un amigo. Si bien muchas referencias y elementos adjuntos proceden de sus producciones propias, también se acoge a las ajenas dentro de la marca Netflix, ya sea por el texto que acompaña o por una referencia a un rasgo de la cultura de consumo en atracón (binge watching) relacionada con Netflix.

Se realizó también un análisis cuantitativo de las series y películas que aparecen en los tuits analizados. El objetivo era ver qué títulos tienen mayor peso en el discurso de @NetflixES. Esto nos daría una primera perspectiva acerca de si las conversaciones que genera y mantiene este perfil se concentran en un número limitado de títulos - de su catálogo de Originales, especialmente-. En total, se suman 256 referencias en 234 tuits, dado que a veces se hace referencia a más de un título por mensaje.

Son 23 los títulos del catálogo que son mencionados más de cinco veces. El título que recibe más menciones o referencias en las conversaciones de @NetflixEs en el mes estudiado es la serie Black Mirror (48 referencias en total). Le siguen Narcos y Luke Cage (con 20 referencias en total, cada una), "7 años" (12) y Stranger Things (11). Las referencias a las historias del catálogo y algunos de sus elementos podrían servir también para sacar los contenidos del espacio personal en el que pudieron consumirse.

En el gráfico 4 se ve una comparativa entre los tuits informativos y los de comentario, del total de los 256 que incluyen referencias a contenidos del catálogo de 
Netflix. Incluye también una comparativa entre las referencias al catálogo de Originales y las referencias a otros contenidos disponibles en España a través del servicio. Los títulos llamados "Originales" son aquellos que surgen bajo el amparo de la marca Netflix, los contenidos de producción propia. El objetivo de este gráfico es ver el peso de los contenidos, partiendo de la hipótesis de que los contenidos marca Netflix estarán más presentes en las interacciones de la cuenta, tanto en las publicaciones informativas como en los comentarios.

\section{Gráfico 4. Tuits con referencias a contenidos del catálogo Netflix España}

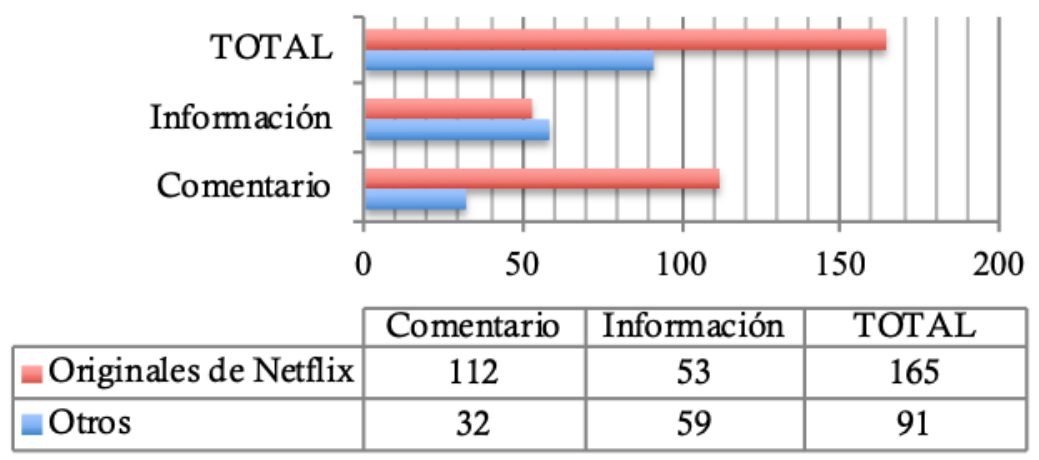

Fuente: elaboración propia

En este gráfico podemos ver que se cumple la hipótesis de que las publicaciones de la cuenta están apoyadas principalmente en contenidos del catálogo de Originales. No obstante, hay que apuntar que, en número de tuits informativos, los relacionados con contenidos ajenos superan ligeramente en menciones a los de Originales. Aunque en total los contenidos de producción propia predominan, lo hacen por los tuits de tipo comentario.

Asimismo, un análisis de la relación entre los temas -el total de los que veíamos en el gráfico 3- y el tipo de tuit -publicación o respuesta- nos permite observar que los usuarios tienden a usar este canal para pedir información sobre los contenidos -en especial los no originales de Netflix- y manifestar su preocupación por disponer de ciertos títulos. Los espectadores globales son cada vez más conscientes de los programas de televisión disponibles más allá de sus fronteras geográficas y son más exigentes sobre la posibilidad de tener acceso a ellos.

Finalmente, como últimas observaciones, conviene aludir a la forma y estilo de los mensajes: se podría decir que el elemento más notable de las publicaciones de la cuenta de@NetflixES es su tono y su humor. La cuenta se caracteriza por mensajes en un tono cercano y amistoso. Las interacciones apuntan en su mayoría a una intención de reforzar el conocimiento que la marca tiene de sus usuarios. Ese conocimiento sirve como base de la cercanía que transmite y, en cierta forma, se podría decir que asienta la imagen de la marca como personificación de una oferta satisfactoria.

Por ejemplo, como veíamos en el gráfico 3, uno de los temas más recurrentes de las publicaciones de @NetflixEs gira en torno a los hábitos de consumo de los usuarios del servicio. Este tipo de tuit incluye menciones principalmente a la práctica del binge- 
viewing, pero también a otros comportamientos y actitudes de los usuarios ante los espacios o tiempos de visionado. Muestran, en general, comprensión acerca de la impaciencia y el desorden de los "atracones" o "maratones" de los usuarios y sus consecuencias. Se podría decir que incluso animan estos comportamientos. Así se puede observar, por ejemplo, en las siguientes imágenes 2 y 3 :

\section{Imagen 2. Tuit @NetflixEs (7-10-2016)}

Netflix España ENetflixES - 22 oct. 2016

"Ahora que llueve voy a aprovechar para quedarme todo el dia en casa viendo series".

Tú el pasado verano:

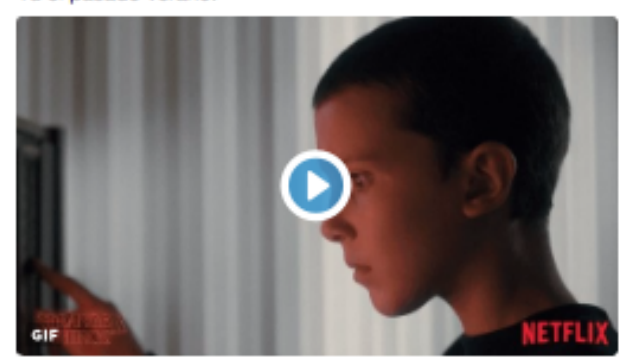

4 $8 \div 239 \div 500$

Imagen 3. Tuit respuesta de @NetflixEs (15-10-2016)
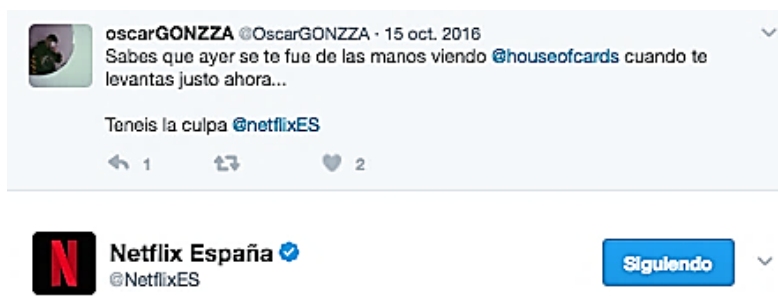

@OscarGONZZA

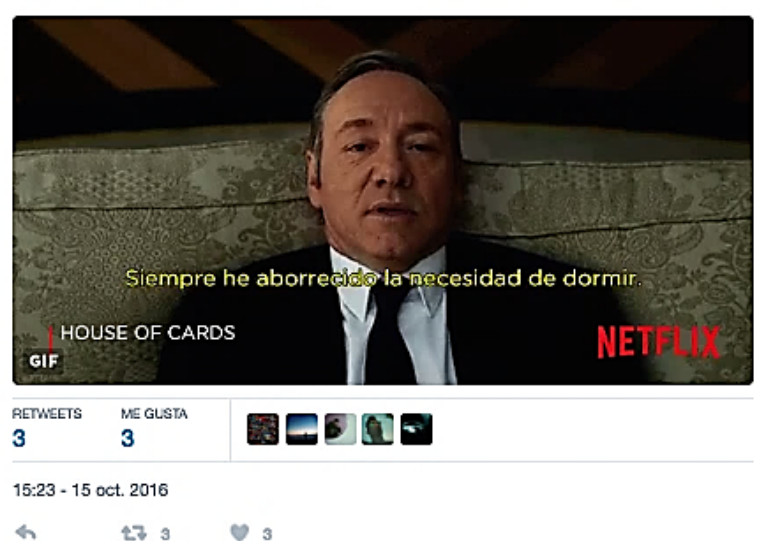




\section{Conclusiones}

El estudio del caso, a la luz del marco teórico propuesto, permite proyectar algunas tendencias en el uso de Twitter por parte de los servicios de video bajo demanda. Es cierto que la proyección de la marca en el caso Netflix se ha hecho de forma constante y aprovechando tiempos y circunstancias favorables que tal vez sean únicos y difíciles de reproducir; por otro lado, el estudio se ha centrado en la marca, y no disponemos de datos de respuesta de la audiencia. Sin embargo, pensamos que pueden extraerse algunas lecciones.

Como veíamos en la revisión de la literatura, el consumo individual puede dificultar la opción de comentar lo visionado por cuenta propia y las redes sociales ofrecen un espacio en el que se motiva la conexión con las historias y se da pie a los usuarios para actuar como fans. De hecho, toda la cuenta de Netflix da la impresión de estar pensada para usuarios comprometidos, ya que está llena de comentarios que solo se comprenden si se conocen los contenidos estrella.

La intención de generar conversación lleva a definir un objeto del que muchos puedan participar. El consumo de los usuarios sigue apoyándose en un principio de consumo social. A pesar de la disponibilidad de una variedad muy amplia de contenidos de entretenimiento, un número reducido de éxitos es suficiente para disfrutar de la experiencia social. Experiencia que adquiere un estilo informal, lleno de humor, que refuerza la personalización de la marca. La personalización está reforzada por el tema principal de conversación, los contenidos, de manera que se favorece el engagement.

Finalmente, los contenidos se revelan como el objeto principal del discurso, poniendo de manifiesto su centralidad en un servicio de video bajo demanda. Siendo esto así, la marca, personalizada con voz propia en Twitter, habla de ellos con sus seguidores construyendo un espacio social que refuerza la relación. Y de nuevo, content is King. 


\section{Referencias}

Aaker, J. L. (1997). Dimensions of brand personality. Journal of Marketing Research, 34(3), 347-356. Retrieved from https://ezproxyprd.bodleian.ox.ac.uk:7316/docview/235235096/fulltextPDF/508EE015F27A4C 7DPQ/1?accountid=13042

De Vries, L., Gensler, S., \& Leeflang, P. S. H. (2012). Popularity of Brand Posts on Brand Fan Pages: An Investigation of the Effects of Social Media Marketing. Journal of Interactive Marketing, 26, 83-91. https://doi.org/10.1016/j.intmar.2012.01.003

Delgado von Eitzen, C. (2016, octubre 15). Perfil del usuario de Twitter en España en 2016. Ch. Recuperado a partir de http://www.christiandve.com/2016/10/perfilusuario-Twitter-espana-resultados

Deller, R. (2011). Twittering on: Audience research and participation using Twitter. Participations: Journal of Audience \& Reception Studies, 8(1), 216-245. Retrieved from http://www.participations.org/Volume 8/Issue 1/PDF/deller.pdf

Drury, G. (2008). Opinion piece: Social media: Should marketers engage and how can it be done effectively? Journal of Direct, Data and Digital Marketing Practice, 9(3), 274-277. https://doi.org/10.1057/palgrave.dddmp.4350096

Fournier, S. (1998). Copyright (C) 1998. All rights reserved. Journal of Consumer Research, 24, 343-373. Retrieved from http://bv.unir.net:2428/ehost/pdfviewer/pdfviewer?vid=1\&sid=59299120-bb2540ea-941f-8cb9670ef41e\%40sessionmgr104

González-Neira, A., \& Quintas-Foufe, N. (2015). Twitter, la televisión social y la audiencia social ¿Por qué triunfa un espacio en la audiencia social? La Coruña (España). Retrieved from http://ruc.udc.es/dspace/bitstream/handle/2183/15401/gonzalez_neira_ana_2014 _audiencia_social.pdf? sequence $=5 \&$ isAllowed $=\mathrm{y}$

Greer, C. F., \& Ferguson, D. A. (2011). Using Twitter for Promotion and Branding: A Content Analysis of Local Television Twitter Sites. Journal of Broadcasting \& Electronic Media, 55(2), 198-214. https://doi.org/10.1080/08838151.2011.570824

Harrington, S., Highfield, T., \& Bruns, A. (2013). More than a Backchannel: Twitter and Television. Participations: Journal of Audience \& Reception Studies, 10(1), 405409. Retrieved from http://www.participations.org/Volume 10/Issue 1/30 Harrington et al 10.1.pdf

Herrero, M. (2009). La economía del producto audiovisual en el mercado de la comunicación. Comunicacion Y Sociedad, 22(1), 7-31. 
Highfield, T., Harrington, S., \& Bruns, A. (2013). Twitter as a Technology for Audiencing and Fandom. Information, Communication \& Society, 16(3), 315339. https://doi.org/10.1080/1369118X.2012.756053

Highfield, T., \& Leaver, T. (2016). Instagrammatics and digital methods: studying visual social media, from selfies and GIFs to memes and emoji. Communication Research and Practice, 2(1), 47-62. https://doi.org/10.1080/22041451.2016.1155332

Jenkins, H., Ford, S., \& Green, J. (Joshua B. (2013). Spreadable media : creating value and meaning in a networked culture. New York University Press.

Jenner, M. (2016). Is this TVIV? On Netflix, TVIII and binge-watching. New Media \& Society, 18(2), 257-273. https://doi.org/10.1177/1461444814541523

Kelleher, T. (2009). Conversational Voice, Communicated Commitment, and Public Relations Outcomes in Interactive Online Communication. Journal of Communication, 59(1), 172-188. https://doi.org/10.1111/j.14602466.2008.01410.x

Kent, M. L., \& Taylor, M. (1998). Building Dialogic Relationships Through the World Wide Web. Public Relations Review, 24(3), 321-334. Retrieved from https://ezproxy.si.unav.es:3497/S036381119980143X/1-s2.0S036381119980143X-main.pdf?_tid=2ada34bc-0bf6-11e8-b00e00000aab0f02\&acdnat $=1518001434 \_56 \mathrm{c} 1313 \mathrm{f} 24 \mathrm{e} 5 \mathrm{a} 35955851179 \mathrm{ef} 9 \mathrm{~d} 935 \mathrm{f}$

Kim, D., Nam, Y., \& Kang, S. (2010). An analysis of corporate environmental responsibility on the global corporate Web sites and their dialogic principles. Public Relations Review, 36(3), 285-288. https://doi.org/10.1016/J.PUBREV.2010.04.006

Li, Z. (2015). Relationship maintenance on Twitter: implications from loyalty leaders. Journal of Communication Management, 19(2), 184-202. https://doi.org/10.1108/JCOM-07-2013-0055

Lotz, A. D. . 1974-. (2007). The television will be revolutionized. Retrieved from https://ezproxy-prd.bodleian.ox.ac.uk:7357/cgi/t/text/textidx?c=acls;idno=heb08239

Lovejoy, K., Waters, R. D., \& Saxton, G. D. (2012). Engaging stakeholders through Twitter: How nonprofit organizations are getting more out of 140 characters or less. Public Relations Review, 38(2), 313-318. https://doi.org/10.1016/J.PUBREV.2012.01.005

Marwick, A. E., \& Boyd, D. (2011). I tweet honestly, I tweet passionately: Twitter users, context collapse, and the imagined audience. New Media \& Society, 13(1), 114133. https://doi.org/10.1177/1461444810365313 
Rybalko, S., \& Seltzer, T. (2010). Dialogic communication in 140 characters or less: How Fortune 500 companies engage stakeholders using Twitter. Public Relations Review, 36, 336-341. https://doi.org/10.1016/j.pubrev.2010.08.004

Saffer, A. J., Sommerfeldt, E. J., \& Taylor, M. (2013). The effects of organizational Twitter interactivity on organization-public relationships. Public Relations Review, 39(3), 213-215. https://doi.org/10.1016/j.pubrev.2013.02.005

Seltzer, T., \& Zhang, W. (2010). Toward a Model of Political Organization-Public Relationships: Antecedent and Cultivation Strategy Influence on Citizens' Relationships with Political Parties. Journal of Public Relations Research, 23(1), 24-45. https://doi.org/10.1080/1062726X.2010.504791

Sundstrom, B., \& Blake, A. (2017). The art of engagement: dialogic strategies on Twitter. Journal of Communication Management, 21(1), 17-33. Retrieved from http://ezproxy.si.unav.es:2718/doi/pdfplus/10.1108/JCOM-07-2015-0057

Tolins, J., \& Samermit, P. (2016). Research on Language and Social Interaction GIFs as Embodied Enactments in Text-Mediated Conversation GIFs as Embodied Enactments in Text-Mediated Conversation. Research on Language and Social Interaction, 49(2), 75-91. https://doi.org/10.1080/08351813.2016.1164391

Tryon, C. (2015). TV got better: Netflix's original programming strategies and binge viewing. Media Industries Journal 2.2, 2(2), 104-116.

Watkins, B. A. (2017). Experimenting with dialogue on Twitter: An examination of the influence of the dialogic principles on engagement, interaction, and attitude. Public Relations Review, 43, 163-171. https://doi.org/10.1016/j.pubrev.2016.07.002

Wood, M. M., \& Baughman, L. (2012). Glee Fandom and Twitter: Something New, or More of the Same Old Thing? Communication Studies, 63(3), 328-344. https://doi.org/10.1080/10510974.2012.674618 